\title{
TEMÁTICA FOLCLÓRICA EÑ LA LITERATURA ASIÁTICA (ORIENTE EXTREMO). RELACIÓN CON LOS MITOS GRIEGOS
}

\author{
Dra. D. ${ }^{a}$ Inmaculada Berlanga Fernández \\ Jaén. España
}

\section{INTRODUCCIÓN}

\section{El Folclore como ciencia}

Aunque el material folclórico es tan viejo como la propia humanidad, el nombre y el estudio científico es joven. Con la llegada, en todas las naciones, del movimiento Romántico, se empieza a recoger todo lo que se considera en trance de desaparecer. Inician el camino de la ciencia folclórica -aún sin saberlo ellos- los hermanos Grimm, que recopilan por toda Alemania cuentos y leyendas que publicarán en 1812. Al compararlos con los de otros paises, ven que los mismos temas de las orillas del Rin, los contaban pastores de Francia, Irlanda o Escandinavia. Al seguir investigando, encuentran idéntico fondo en otras tradiciones culturales, y de manera señalada, en los mitos clásicos.

Este interés, común a varios paises, por recoger tradiciones populares, intensificado por los Románticos, se irá convirtiendo en la segunda mitad del s. XIX en una ciencia autónoma, que sin embargo comparte su campo de investigación con otras disciplinas afines, como la Etnología, Antropología, Mitologia, Historia Lingüística, etc. Es en 1846 cuando el Folclore como ciencia recibe su denominación definitiva: el inglés W. Thoms envía una carta al director de The Ateneum, revista que habia mostrado un interés por "las Antigüedades populares o la Literatura Popular", agradeciendo el interés por la temática que Thoms propone designar con una palabra anglosajona, Folk-lore, el saber del pueblo. En 1878 surge la primera asociación, la Folklore Sociely inglesa, que acepta esta denominación. Su función se concreta en el artículo primero de sus estatutos: "La Folklore Society tiene por objeto la conservación y publicación de las tradiciones populares, baladas legendarias, proverbios locales, dichos, supersticiones y antiguas costumbres (inglesas y extranjeras), y demás materias concernientes a esto". Pronto estudiosos de diferentes paises, especialistas en las materias afines antes citadas, ofrecieron su colaboración.

Así pues, también a mediados del siglo XIX, el dominio del antiguo indio (védico y sánscrito) y su evidente relación con lenguas europeas ocasiona y origina la comparación 
entre unas y otras mitologías: Max Müller, alemán que trabaja en la Universidad de Oxford, publica su Comparative Mythology. Otros muchos trabajos se siguen de otros folcloristas, con distintos puntos de vista y distintas teorias: Tylor, A. Dundes, Th. Benfey, E. Cosquin, W. A. Clouston, etc. En la universidad de Cambridge surge un gran folclorista: Sir James George Frazer -editor de Apolodoro en The Loeb Classical Library (1921)-. Fue la primera figura de la escuela evolucionista, y su libro, The Golden Bough,' ejercerá una gran influencia en la Antropología, en la literatura y en los estudios del folclore. ${ }^{2}$

\section{Nuestra investigación}

No es dificil percibir la conexión entre la mitología más conocida -la del pueblo heleno-, y la de otras culturas y civilizaciones, como es el caso de la asiática, rica en temática folclórica. Como se ha indicado en el título de nuestra ponencia, se pretende rastrear en estas literaturas populares, y presentar coincidencias temáticas entre sí. Con este objetivo, en un primer apartado se introduce el tema con la descripción de los rasgos y elementos que son propios de las literaturas populares. Se examinan las coincidencias de temas y lugares comunes bajo la posibilidad de una transmisión mítica o de desarrollo independiente, deteniéndonos en el concepto de arquetipo aplicado a la literatura folclórica. Cierra el estudio una breve referencia a la presencia de lo folclórico en las letras griegas.

En un segundo apartado argumentamos nuestro estudio con el tópico del descenso al mundo subterráneo, recogido en una leyenda de la mitología griega y otra de la mitologia japonesa. Enumeramos otros cinco tópicos, entre los muchos que coinciden en estas literaturas, y finalizamos con unas conclusiones.

Señalamos a continuación una relación por paises de los folcloristas del continente asiático. No pretendemos agotar el tema con este listado; recogemos los folcloristas más sobresalientes y que frecuentemente citamos en este trabajo.

PAÍSES ASIÁTICOS.

Arabia: R. F. Burton, V. Chauvin.

Armenia: M. Ananikian.

China: W. Eberhard, J. C. Ferguson, H. A. Giles, D. C. Graham, E. T. C. Werner.

India: E. B. Cowell, A. B. Keith, G. P. Malalasekera, J. J. Meyer, N. M. Penzer, C. H. Tawney y S. Thompson-J. Balys.

Japón: M. Anesaki, M. Ikeda, A. B. F. Mitford.

Mesopotamia: P. Jensen, J. B. Pritchard, L. Spence, A. Ungnad-H. Gressman.

Persia: A. J. Carnoy, J. Charpentier.

Pueblo hebreo: M. J. bin Gorion, J. G. Frazer, Sv. Liljeblad, D. Neuman, I. B. Singer.

1 La primera edición de esta obra vio su luz en 1890, pero es la $3^{2}$ edición en 12 volúmenes (1911-1915), la que pronto se convirtió en la más citada y más utilizada. La versión resumida del mismo Frazer está traducida al español, La rama dorada, en Fondo de Cultura Económica, México, 1944. $2^{\mathrm{a}}$ ed., 1951.

2 Una descripción más completa de la mitologia comparada en sus comienzos, y de la teoria de Müller, nos la ofrece C. Garcia Gual, Introducción a la mitologia griega, Madrid, Alianza Editorial, 1992; v. concretamente el cap. "Interpretaciones". 


\section{LAS LITERATURAS FOLCLÓRICAS}

\subsection{Elementos y rasgos propios de las literaturas populares ${ }^{3}$}

Entendemos por literatura folclórica cualquier literatura transmitida oralmente, no fijada en mucho tiempo por escrito, ni ligada a un autor concreto, esto es, anónima, y que, conservada por la tradición popular, ha sobrevivido desde hace largo tiempo como patrimonio del pueblo. Se caracteriza a su vez por la espontaneidad y sencillez, y como fruto de su tradición oral el estilo y la dicción es formular.

En contraposición, la literatura culta es una literatura escrita, de autor conocido o que -en el caso de ser anónima- puede estar ligada a un nombre y a una tradición asimismo escrita, y está caracterizada por cierta elaboración más compleja y artificiosa.

Es propio de la literatura folclórica obtener muchos de sus temas de la observación de la naturaleza y de otras realidades extraliterarias, y con frecuencia exagera y agranda tales tópicos. Podriamos señalar como sus fuentes: a) La naturaleza (observación de la fauna, flora, actividad atmosférica, etc); b) El entorno social, el tipo de organización social de cada comunidad; c) La psique humana, en su vertiente más elemental: instintos primarios y generales que caracterizan al ser humano (nacimiento, más allá, edades de la vida humana, el sexo); d) Todo lo que es excepcional o maravilloso (gigantismo, albinismo, etc). Se aprecia además una tendencia a la morbosidad, a lo cruel, a lo atroz.

Por todo esto, es frecuente la existencia de una temática común en distintos paises y tiempos debido, bien a un desarrollo independiente, bien a una transmisión mítica y temática, con influencia de una cultura sobre otra(s).

La literatura culta, por su parte, muy ligada a menudo a la folclórica, incorpora a su temática bastantes de estos lugares comunes, a los que muchas veces depura y estiliza.

En algunas ocasiones pues, resultará dificil determinar dónde empieza la culta y dónde acaba la popular, por lo que será necesario hablar de literatura semiculta o semifolclórica. Esto es lo que ocurre, en general, con la literatura griega de la época arcaica, con la poesía de Berceo y el Arcipreste de Hita y con El Decamerón de Bocaccio, por ejemplo.

\subsection{Transmisión mítica y desarrollo independiente}

Según lo antes dicho, muchos de los elementos que componen estas tradiciones se encuentran repetidos parcial o sustancialmente en la tradición literaria de los cinco continentes. Existen coincidencias temáticas en culturas y tiempos muy diversos. Por ello resulta a veces dificil asegurar si un tema concreto tiene su origen en una sola fuente $-y$ ha sido posteriormente objeto de una transmisión oral-, o, por el contrario, se debe a una invención original independiente.

3 Para una bibliografia referencial sobre el tema, cf. D. Estébanez Calderón, Diccionario de términos literarios, Alianza Editorial, Madrid, 1996, s.v. "literatura popular", "oral" (literatura); cf. asimismo, P. Zumthor, Introducción a la poesia oral, 1991, trad. esp., Ed. Taurus, Madrid, 1991. 
Cuando un tema dimana o procede de realidades muy cotidianas y ajenas a toda ficción literaria, es corriente que surja en diversas naciones y tiempos por desarrollo independiente. Sirvan de ejemplo, dentro de los tópicos truculentos, el causar ceguera como castigo o venganza; el comparar lo efimero de la vida humana con las hierbas, hojas y flores; la piedad filial de las cigüeñas; 0 , para no eternizarnos con más casos, el catálogo de fuerzas y adalides de un ejército. ${ }^{4}$

Cuando el tema es muy concreto y dos obras literarias están en clara interdependencia, por el contrario, es fácil ver una transmisión temática. Tal es el caso de ciertos tópicos de la poesía bucólica, como el del pastor que se jacta de su riqueza ante el ser amado (v. Teócrito, XI, 34-40; Virgilio, Égloga II, 19-27), o aquél en que el pastor encomienda el rebaño al zagal, mientras él va a cantar a su amor (v. Teócrito, III, 3-5; Virgilio, Égloga IX, 23-25), etc.

Debemos tener en cuenta que la influencia literaria puede ser influencia cuantitativa e influencia cualitativa. ${ }^{5}$

\section{Influencia cuantitativa.}

Dentro de esta primera clase a su vez podemos diferenciar en:

1) cuantitativa total, si el influjo de una obra sobre la otra es global (La Odisea sobre la primera mitad de la Eneida; El Hipólito de Eurípides sobre las Fedra de Séneca y Racine).

2) Cuantitativa parcial, si la dependencia se traduce en:

a) un eco de alguna importancia, pero ya desligado de la fuente originaria (el Amphitryon de Molière respecto al mito de Anfitrión griego, verbigracia);

b) un tópico literario muy evolucionado (el soneto de Lope cuyo comienzo es "¿_Qué tengo yo que mi amistad procuras?..." con relación al tópico helenístico del "paraklausíthyron", por ejemplo;

c) una mera alusión, cita o mención (las múltiples referencias a la mitología clásica que hace F. García Lorca en su obra poética -"Pegaso", "Pan", "Venus", etcponemos por caso).

4 Cf. respectivamente: para el "topos" de la ceguera, Hom. Il., 559; Esquilo, Etrm., 186; J. A. McCulloch, Eddic Mithology, Boston, 1930, 322; A. N. Afanásiev, Cuemos Populares Rusos, trad, esp., Madrid, 1986, 75; W. Shakespeare, El rey Lear, Acto III, escena VII; para el símil sobre la brevedad de la existencia, Hom., II. VI, 146-149; Baquilides, V, 64-67; Biblia, Salmos, 102, 5; Tochihuitzin Coyolchiuhqui, "Venimos a sonar", cf. M. León-Portilla, Trece poetas del mundo azteca, México, 1967, 131; J. Manrique, Coplas a la muterte de su padre (en la estrofa XV: “...qué fueron sino verduras las eras?..."); con respecto a las piadosas cigüeñas, Sóf., El., 1058; Aristóf., Aves, 1355; Dante, La Divina Comedia, "Purg". XXV 10; F. de Rojas, La Celestina, Acto Cuarto; J. Hernández, Martin Fierro, vv. 7019-7024; sobre el catálogo de tropas y guerreros, Hom., Il., II, 494763 y 816-877; Heródoto, VII, 61-99; Biblia, "Josué", 1I, 1-23; El Cantar de Roldán, LXIX-LXXXIX; Cervantes, Quijote, Primera Parte, cap., XVIII; y un largo etcétera para unos y otros temas.

5 Este aspecto nos pone en relación con la Intertextualidad, término utilizado por una serie de críticos (J. Kristeva, A. J. Grimas, R. Barthes, G. Genette, J. Ricardou, etc) para referirse al hecho de la presencia de un determinado texto, de expresiones y rasgos estructurales, estilisticos, de género, etc, procedentes de otros textos y que ha sido incorporado a dicho texto de diversas formas. Un estudio actual y completo del tema lo encontramos en G. Genette, Palimsestos, Seuil, 1982, trad. esp., Ed. Taurus, Madrid, 1989. 


\section{Influencia cualitativa}

El plano cualitativo es subdivisible asimismo en:

1) Influencia directa, si el autor influenciado se inspira en la primera fuente, sin autor intermediario (El pasaje de Virgilio, Eneida, II, 3 -"infandum, regina, iubes, renovare dolorem"-, que depende muy directamente de Odisea, VII, 241-242.

2) influencia indirecta, cuando hay uno o varios autores intermediarios entre la fuente originaria y el autor influenciado (Garcilaso, Egloga I, 169-181 depende indirectamente de Teócrito, XI, 34-40, porque su fuente intermedia es, sin duda, Virgilio, Egloga II, 19-27).

Otras muchas veces hay que hablar de desarrollo independiente; ya hemos señalado cómo la literatura folclórica obtiene muchos de sus temas de la observación de la naturaleza y de otras realidades extraliterarias; la mente humana reacciona ante circunstancias semejantes de manera similar. Sin embargo es de notar cómo un elevado número de estudiosos y tratadistas han ignorado esta realidad o han intentado justificar las múltiples coincidencias temáticas hablando de influencias y dependencias literarias En esta línea se encuentra la tendencia historicista, que pretende explicar la enorme extensión geográfica de dichas analogías como consecuencia de las migraciones; el origen geográfico quedaria situado en las vertientes del Cáucaso. Esto es válido para no pocos casos, con orígenes concretos y vías y fechas concretas de difusión ${ }^{6}$. Pero no justifica todos los lugares comunes.

\section{I.3. El problema de los arquetipos}

En literatura folclórica se llama "arquetipo" a la primera forma histórica de un cuento, canción, etc. ${ }^{7}$ En la práctica, podría decirse que el arquetipo es un ente de razón. Querer remontarse a la génesis de un motivo literario podría calificarse de tarea inalcanzable y sobre todo podria incurrirse en una notable falta de método científico. Podemos traer a nuestro estudio la original concepción del arquetipo que hace A. R. Almodóvar para sus cuentos. ${ }^{8}$ Utiliza el clásico binomio lengua/habla y lo aplica a su explicación del arquetipo/distintas versiones. ${ }^{9}$ Él hace una labor de restauración de todas las versiones que de un mismo cuento tiene, e intenta abstraer lo que explica la sintesis de la totalidad del cuento. Esta abstracción es el arquetipo, como la lengua es la abstracción de las distintas hablas. Las hablas son versiones de la lengua concreta: las versiones de un cuento son pues como el habla, y el arquetipo es como la lengua.

Valorando la originalidad de dicha explicación, no deja de ser un ente de razón.

6 Cf. F. R. Adrados, "Fábula y cuento popular de tradición antigua en los Balcanes", EC XXXIII (n_ 100)(1991), pp. 63-80. nidad. Habla es el peculiar uso que cada miembro de la comunidad hace de su lengua. 
Nos parece más acertado la norma que propugna W. R. Halliday, ${ }^{10}$ para evitar tomar por variantes de un mismo relato lo que en realidad pueden ser dos historias o narraciones independientes, con algunas afinidades o coincidencias debidas a desarrollo independiente. Consiste en reservar el término de dependencia literaria, para aquellas historias que repiten sustancialmente los mismos argumentos y que por la misma serie de incidentes, dispuestos en el mismo orden lógico de interés, podrían ser considerados como variantes de una misma narracion. "Only stories which substantially repeat the same plot, that is to say the same series of incidents arranged in the same logical order of interest, in which the variation is limited to obvious or accidental omissions or modifications, can fairly be trated as variants of the same tale"."

En muchas ocasiones se puede concluir que esos lugares comunes reflejan más bien la universalidad de la condición humana; y su desarrollo paralelo "la conexión del folclore con la economía de la vida material."'12

\section{Temática de doble desarrollo.}

Es posible que un tema nos llegue a través de la literatura culta y que aparezca a la par y sea un desarrollo paralelo e independiente, en el ámbito de las literaturas folclóricas. Sirva de ejemplo el tema de la grulla que huye del temporal. Aparece en Fray Luis de León ("...ya el ave vengadora/ del Íbico navega los nublados/..."), Milton ("...with clang despise the ground, under a cloud in prospect...") y en otros muchos autores de la literatura culta (J. M. Pereda, Peñas arriba, por ej.). Puede haber aqui ecos de varios pasajes de la literatura griega (Homero, Iliada, III, 3-4; Hesíodo, Trabajos, 448-451; Virgilio, Eneida, X, 264-266 y Geórgicas, I, 373-375), pero también por desarrollo independiente, puede aparecer este tópico, que procede de la observación de la naturaleza, por lo que está documentado en muchas literaturas populares y cultas. ${ }^{13}$

10 Cf. W. R. Halliday, Greek and Roman Folclore, reimp. New York, 1963, p. 80.

11 Ibidem.

12 Cf. V. Propp, Las raices históricas del cuesto, Madrid, 1974, p. 535.

13 C. M. Anesaki, Japanese Mythology, Boston, 1928, 323; S. Thompson, Tales of North American Indians, Cambridge (Mass.), 1929, 340, $\mathrm{n}^{\circ}$ 277; J. M. de Pereda, op. cit., Madrid, $5^{2}$ ed., 1969, p. 98; etc. Y para otros ejemplos: el tópico de mencionar la tez morena como rasgo físico negativo, propio de plebeyos campesinos: aparece en El Cántico Espiritual de S. Juan de la Cruz, y puede, lógicamente, proceder del Cantar de los Cantares, I, 6, o también de Teócrito, Idilios, XXIII, 30-31 y X, 26-29; o bien de Virgilio, Égloga, II, 16-17. Y lo más probable es que $\mathrm{S}$. Juan tome el tópico de una de estas fuentes, pero también puede ocurrir que el tema aparezca, como tópico folclórico, por desarrollo independiente o paralelo, porque este "tópos" surge en las canciones populares de Castilla ("blanca me era yo/ cuando fui a la siega;/ diome el y ya soy morena"); Jaén ("desde mi casa a la iglesia/también quiero yo una parra/ para cuando vaya a misa/no me dé el sol en la cara"); en Rosalia de Castro, Cantares gallegos ("Castellanos de Castilla,/ tratade ben aos gallegos;/ cando van, van como rosas;/ cando vén, vén como negros"); en Lope de Vega, El gran duque de Moscovia, VII.

Por lo mismo, en la misma obra citada de S. Juan de la Cruz, la mención de la tórtola (vv. 163-165) puede estar inspirada en Teócrito, VII, 141 o Virgilio, Egloga, I, 58, por ejemplo, pero también procede recordar que aqui hallamos un tópico muy extendido en las distintas literarturas populares (Romancero español, en La Biblia, Isaías, 38, 14; Ezequiel, 7, 16; Cantar de los Cantares, I, 12; P. Sébillot, Revie des Traditions Populaires, III, 159 y ss.)

Cf. más ejemplos en M. Benavente, "Influencias de la literatura clásica en la Obra de S. Juan de la Cruz", en J. Higueras Maldonado (ed.), San Juan de la Cruz y Jaén, 1992, pp. 387-399, cf. en especial, pp. 391-394. 


\section{Semejanza por mera y rara coincidencia.}

De otro lado, existen a veces curiosos parecidos y paralelismos en que más bien parece hay que hablar de extraña coincidencia. Tal es el caso de la similitud señalada por Lévy, ${ }^{14}$ entre un pasaje del "Poema de Gilgamésh" y Sófocles, fragmento 956 Pearson. Lo mismo podría afirmarse sobre dos textos pindáricos $\mathrm{y}$ dos de Ben Quzmán, estudiados por Fernández Galiano. ${ }^{15}$ Otras veces se puede apuntar como posible, mas no como probable, una influencia literaria, siempre dentro de una sana cautela. Este puede ser el caso entre la semejanza existente entre Sofocles, Filoctetes, 356-358, y Tito Livio, XXI, 4, 1-2. También se señala en este artículo el parecido entre Rigveda, I, 115, 2 y Hesíodo, Trabajos, 580-581.

\subsection{Lo folklórico en las letras griegas}

En la literatura griega observamos que casi la totalidad de su temática, procede del fondo de leyendas y tradiciones mitológicas que el pueblo heleno conservaba desde tiempos inmemorables. Por lo que se refiere al cuento en Grecia nos es prácticamente desconocido. ${ }^{16}$ No se han conservado repertorios griegos de cuentos (como los de mitos o fábulas) y tampoco parece que los haya habido en forma considerable. El único relato con forma de cuento que conservamos es la fábula de Eros y Psique de Apuleyo: el carácter de cuento se aprecia por ejemplo, en el inicio: "erat in quadam civitate rex et regina. Hi tres numero filias... habuere"; hay semejanza con las formulas introductorias de los cuentos en otras tradiciones. Ahora bien, aunque es evidente que Apuleyo ha querido darle a este relato el aspecto de un cuento tradicional, no sabemos si la historia es invención suya o si realmente ha transformado (y refinado) un cuento popular.

La evidencia que tenemos sobre el cuento griego se reduce pues a, testimonios sobre cuentos en Grecia, dificiles de interpretar, o bien elementos de cuentos en obras de otros géneros, muy numerosos por cierto, y documentados en otras tradiciones: elementos de los "Marchën" de la literatura universal, se reconocen en los argumentos de las obras griegas, de suerte que se puede constatar la ingente cantidad de paralelismos exactos, elementos, temas, que parecen ser común al folclore griego y al posterior. ${ }^{17}$ Basta una lectura de las principales colecciones de este género folclórico, especialmente de la más conocida, la de los hermanos Grimm. En estos cuentos reconocemos temas genuinamente griegos -La historia de Melampo encuentra paralelismo exacto en el cuento 17 de Grimm, "la serpiente blanca"-, o claras referencias a personajes o temas (es el caso del cuento $\mathrm{n}^{\circ} 4$, "Penélope", y el tema, el marido que regresa en el instante preciso para impedir que la esposa, que le supone muerto, se case con otro), o bien, elementos que se encuentran en la leyenda griega (sirva de ejemplo, el tópico de la prenda de la vida de la historia de Meleagro, que aparece en los cuentos 6 y 7 "Punkchin" y "Sansón"). Podríamos continuar citando un extenso catá-

14 Cf. G. R. Lévy, The Sivord from the Rock, London, 1953, p. 123.

15 Cf. "Píndaro y Ben Quzmán. Coincidencia, no influencia", en EC VIII, 1964, pp. 210-211.

16 Para un "status quaestionis" en torno al "Märchen" en la literatura griega, cf. E. Mensching, "Marchēn", en Der kleine Pauly, t.III (1979), coll. 866-8.

17 Cf. H. J. Rose, Mitologia griega, trd. esp. Barcelona, 2a ed., 1973 (“Märcben” en Grecia e Italia), pp. 283 ss. 
logo de transformaciones, metamorfosis, adivinanzas, hazañas de héroes, intervenciones de animales, hechos maravillosos, etcétera, comunes al folclore griego y al posterior.

Concretamente, vamos a analizar la presencia de dichos tópicos en la literatura asiática del extremo oriente en relación con estos mitos.

Por todo esto, insistimos una vez más en el hecho de que la mayoría de los temas literarios tienen su origen en realidades cotidianas -la naturaleza, el entorno social y cultural, la psicología más elemental del ser humano-, que son normalmente deformadas o exageradas al incorporarse al relato en cuestión.

\section{TÓPICOS FOLCLÓRICOS EN LA LITERATURA GRIEGA Y ASIÁTICA}

\section{1. El tema del descenso al mundo subterraneo en la mitología griega y en la litera- tura asiática del extremo oriente}

Sabido es que el tema del viaje al otro mundo, realizado además por un ser vivo que luego torna en vida al lugar terrenal y de los vivientes, es uno de los más frecuentes tópicos en las literaturas populares en todo el mundo. Lo hallamos, en efecto, dentro de Europa en los relatos folclóricos de Alemania y Austria, Bretaña, El Caúcaso, Dinamarca, España, Finlandia, Grecia, Inglaterra, Irlanda, Islandia, Noruega y Rusia, verbigracia. Lo encontramos asimismo, en ámbitos asiáticos, por ejemplo en la India, Japón, Mesopotamia y Siberia; lo topamos también entre los pieles rojas de América del Norte y del Sur; así como en varios países africanos, y en una amplia zona de Oceanía, que comprende, entre otras, las siguientes naciones: Hawai, Indonesia, Nueva Zelanda, Nuevas Hébridas y Samoa, ponemos por caso.

Por lo que hace a las literaturas cultas, procede recordar que es un tema también bastante repetido, desde la cómica pirueta de Las Ranas aristofánicas, la genial aportación platónica y la obra de Virgilio y Luciano, en la literatura clásica greco-latina; y siguiendo con sátiras como las de Dante y Quevedo, para llegar, al cabo, a las elucubraciones, oníricas vivencias y audaces páginas de un Strindberg, un Antonio Machado o un Priestley. Baste recordar, si nos vamos ahora a las diversas latitudes, que lo mismo hallamos este tema junto al Ecuador como en Groelandia; y que, si se trata de diferentes niveles culturales, lo mismo lo encontramos entre pueblos casi prehistóricos como en algunos de los más bellos mitos helenos. Nada de extraño tiene, por consiguiente, que este tema haya tentado a diversos autores y especialistas. Unos, como E. Mass (Cf. E. Mass, Orpheus, München, 1895), se ha centrado en el subtipo de Orfeo y sus diversos hermanos menores en la literatura popular del cosmos. Otros, como Gayton-Newman (Cf. Gayton-Newman, ob. Cit., 99. V. asimismo Gayton, "The Orpheus Myth in North America", JAFL XLVIII, 263-293) ha abordado el estudio bajo óptica aún más concreta. Hay otros autores, como Luis Gil, que han estudiado la transmisión mítica de una de sus variantes o subtipos (Cf. L. Gil, "Orfeo y Eurídice "versiones antiguas y modernas de una vieja leyenda", en pp. 121-197 de Transmisión mítica, Barcelona, 1975); o bien que han abordado el tema en el ámbito griego, como lo ha hecho 
García Gual (Cf. C. García Gual, "Naufragio en Feacia", Esiudios Clásicos, XII, 1968, 415 ss.), o en los textos helenos y los de otras literaturas antiguas, como ha hecho Mariano Benavente (Cf. M. Benavente, "El motivo del descenso al más allá en las letras griegas y en otras literaturas", Sodalitas $n^{\circ} 2,1981,11-20$; y El más allá en las viejas culturas, Jaén, Univ. de Jaén, 1994).

\section{a) LITERATURA GRIEGA: DIONISO EN EL HADES}

Encontramos este relato en Las Ranas de Aristófanes. Hallamos en la primera parte de esta pieza cómica (vv. 1-705), cuya doble estructura es bien conocida, no a un antihéroe sino a dos: el propio dios y su siervo Jantias. Ambos forman una pareja hilarante, aunque su actitud es desigual y se dé la paradoja de que el esclavo sea más decidido -menos cobarde, para hablar con exactitud- y se muestre menos asustado que Baco. Mas conviene hacer hincapié en que topamos aquí otro fácil elemento de comicidad: el disfraz, que implica además una suplantación de personalidad. Dioniso ha adoptado el atuendo de su poderoso hermano Heracles para así ser tomado por él. Se trata de un tema burlesco y cómico que es frecuente en algunos antihéroes. Citemos los casos de villanos disfrazados de ascetas en los "Märchen" de Italia, la India y España .

Otro motivo de comicidad es el miedo que tienen los dos viajeros, que, pese a sentir tal temor, no dejan de realizar, en efecto, un desenfadado descenso al mundo infernal. Por ello ambos tratan de aprovecharse, a la par, de las obvias ventajas que el disfraz de Heracles puede depararles, cuando se les brindan exquisitas viandas y mujeres fáciles; y procuran, en cambio, deshacerse del peligroso atuendo, cuando Éaco y las airadas vendedoras quieren desquitarse de los agravios y atropellos cometidos por el auténtico Heracles, su día.

Pero Aristófanes supo explotar otros recursos literarios hilarantes: el humor negro con que Heracles indica tres expeditivos medios para ir de modo rápido a la morada de los muerto, a saber, ahorcarse, beber cicuta o arrojarse desde la torre del Cerámico; la llegada ante Caronte, lejano preludio del encuentro machadiano con el barquero infernal; el fallido intento de asalariar a un Muerto para que, de camino que realiza su forzosa bajada al Hades, lleve el hato que tanto molesta a Jantias, intento que rebosa asimismo negro humor, anticipo también de algunas escenas de Luciano; y, por último, el irritante coro de las ranas, que dan nombre a esta pieza cómica, sin olvidar la tunda dada a ambos antihéroes y los hábiles recursos de éstos para disimular el dolor que sienten al ser flagelados.

Pero encontramos también aquí el tema del cambio de indumentaria y personalidad entre criado y señor (o criada y señora), al que más arriba hemos hecha referencia y que tiene gran importancia por su frecuencia, en las literaturas populares de muchos países. Lo hallamos, efecto, en los cuentos de Grimm, los de Rusia, España, Arabia, los cosacos, y otros paises.

Otro elemento hilarante es el hecho de que Caronte obligue a bogar al dios Dioniso, que se queja de esta dura y desacostumbrada tarea, cuya molestia parece que se le acrecienta el escuchar el impertinente y continuo croar de los batracios que dan nombre a este pieza. La distinción que Caronte hace entre uno y otro antihéroe y el que mande a Jantias que recorra el camino por tierra, bordeando la laguna, y sin admitirle a bordo de la barca, aparte de posibles razones de economía literaria no está tampoco exenta de cierta comicidad. Los reitera- 
dos espantos que el cobarde numen siente están en semejante nivel de humor que los miedos y terrores experimentados por otros antihéroes aristofánicas y por los sátiros de los dramas satíricos conservados, Los Rastreadores de Sófocles y El Ciclope de Eurípides. Y procede recordar ahora que la cobardía es uno de los rasgos más típicos de cualquier antíheroe, llámese éste Evélpides, Hans, Jack, Peronnik, Nikita o Sancho Panza.

\section{b) LITERATURA ASIÁTICA: EL DESCENSO DE IZANAGI}

Este mito nipón nos habla sobre la pareja divina formada, por Izanami e Izanagi. Mas la divinidad de estos personajes es un tanto relativa, puesto que Izanami, la esposa, fallece después de un desdichado parto. Esto da a estos personajes, quiérase o no, un cierto carácter humano. Humano también nos resulta Izanagi cuando visita a la difunta en el mundo de las tinieblas y allí trata de convencerla para que vuelva con él al mundo terrenal y de arriba. Ella objeta que eso no es posible, porque ha tomado ya alimento en estos ámbitos subterráneos. Tras esta negativa, Izanami se retira a un palacio que posee en este tenebroso lugar y advierte a su marido que no la siga. Izanagi, naturalmente se apresura a ir detrás de ella y se adentra, con una débil llama, en la morada prohibida. Dentro de esta mansión encuentra a Izanami de muy distinta manera a cómo la ha hallado en su primera entrevista. Ahora está roída de gusanos y en terrible descomposición pestilente. Rabiosa por ser descubierta en lo que, al parecer, es su verdadero estado, Izanamí lanza contra el consternado cónyuge a unas espantables diablesas de este mundo infernal, las "shikome". Izanagi, en su huida, se arranca su tocado y lo arroja tras sí. A su contacto con el suelo surgen uvas apetitosas, que despiertan la gula de las diablesas dichas. Por ello se detienen a devorar estos frutos, en tanto que Izanagi prosigue en su fuga. Pero pronto se le aproximan de nuevo. Nuestro héroe se saca el peine derecho de su cabellera y lo tira asimismo a sus espaldas. Del peine surgen retoños de bambú, que constituyen otro tentador aperitivo para las pertinaces "shikome", que ni cesan en su persecución en sus caprichos gastronómicos. Después son enviados y en pos del héroe que huye hasta mil quinientos feroces guerreros. Pero Izanagi no se acobarda. Mantiene a raya a estos nuevos perseguidores con su tremenda espada y luego, en nueva $e$ insólita estrategia, les arroja tres melocotones con los que les fuerza a retirarse ${ }^{18}$.

Mas también Izanagi, con cierta ruda dialéctica japonesa, triunfa en este certamen: pronuncia solemnemente la formula de divorcio y se retira, muy digno, dejando a su ex-esposa hundida, literalmente, en la miseria.

Izanagi no es del todo un triunfador. Se podria objetar, claro está, que al fin y al cabo Izanagi es un dios, pero ya hemos recalcado más arriba que es una deidad poco poderosa y revestida, por contra, de rasgos humanos.

El expediente de bloquear la entrada al infierno con una gran roca nos recuerda a la peña-puerta del cíclope Polifemo y a otros pedrejones y peñas que hallamos en distintos relatos de las literaturas populares y cultas de diversos países y épocas.

18 Esta fruta tiene cierto prestigio, mágico y maravilloso, en algunos "Märchen". Cf., verbigracia, Myths of China, London, 1922, 173 y 270; y D. C. Graham, Songs and Stories of the Ch'uan Miao (Smithsonian Miscellaneous Publications CXXIII n. 1), Washington, D.C., 1954. Es sugerente que estos relatos populares sean del Celeste Imperio, puesto que de la China, en efecto, parece que procede esta planta. Cf. The New Encyc. Britannica, vol. VII de la "Micropaedia", s.v. "peach". 
El divorcio, cuya fórmula ritual trae a colación Izanagi como supremo argumento dialéctico frente a la recalcitrante esposa es asimismo un recurso frecuente en numerosos relatos de las literaturas folclóricas. Como ha quedado dicho anteriormente Izanagi es uno de tantos personajes, femeninos o masculinos, que van al otro mundo en busca de su pareja. Ello le relaciona con Orfeo, el piel roja Á́kut, Savitri e Ishtar, etc.. Mas nuestro héroe, quizá por su híbrida índole de deidad y hombre, no nos resulta ni simpático ni demasiado admirable. Y aunque se le ha llamado a veces, el Orfeo nipón, tal vez lo lejano y exótico de su origen y país implique diferencias notables con el carácter del héroe heleno.

\section{II.2. Otros tópicos}

\section{ADIVINANZAS}

a) Literatura griega: Esquilo, Agamenón, 1112 y 1183 (el coro comenta la manera de hablar de Casandra), fr. 236 (se menciona a la esfinge tebana), Prometeo, 610 (se hace mención de los enigmas); Eurípides, Fenicias, 1507-1508 y Fenicias, 45-54; Píndaro, fr. 177d Snell-Maehler; Platón, Charmides 162b; cf. asimismo en P. Grimal, op. cit., s. u. "Esfinge"; sobre enigmas de los oráculos, cf. H. W. Parke-D. E. W. Wormell, The Delphic oracle, 2 vols., Oxford, 1956, I. The History, II. The Oracular Responses, "passim"; v. asimismo M. Benavente, "Treinta y seis oráculos de Apolo Delfio", Suplem. de Estudios Clásicos, segunda serie de Textos n 1, Madrid, 1966, Estudios Clásicos X (n 48), 1966, pp. 1-22, en especial, 6-11, 13-14, 16, 18-21.

\section{b) Literatura Asiática}

India: N. M. Penzer, The Ocean Story: being C. H. Tawney's translation of Samadeva's Katha Sarit Sagara, 10 vols., London, desde 1923, cf. vol. I, 51; Thompson-J. Balys, Motif and Type Index of the Oral Tales of India, Bloomington (Indiana), 1967, "ad loca"; Japon: H. Ikeda, Motif and Type Index of Japanese Folktales, Ann Arbor (Michigan), Microfilm Service, 1955, "ad loca".

\section{AVES RAPACES ENFRENTADAS A OTRAS MÁS DÉBILES}

a) Literatura griega y latina: Homero, Iliada, XIII, 62-64 y XXII, 139-142; Odisea, XIX, 536-581 y XXII, 302-306; Hesiodo, Trabajos, 203; Lesbios fr. inc. 10 Lobel-Page; Esquilo, Suplicantes 62; Prometeo, 857; Eurípides, Andrómaca, 1140-1141; Herodoto, III, 763; Teócrito, VIII, 57-59; Virgilio, Égloga IX, 13; Ovidio, Metamorfosis I, 506.

b) Literatura asiática: Pueblo indio: G. P. Malalasekera, Dictionary of Pali Proper Names, 2 vols., London, 1937, I, 437 y 613.

\section{MONSTRUO QUE ES PLAGA DE UN PAIS}

a) Literatura griega: lo encontramos ampliamente documentado en torno a la historia de Edipo, con las múltiples referencias a la esfinge, y otros muchos monstruos a los que venció Heracles citados en Las Traquinias y Fragmentos de Sófocles, por ejemplo. También en las referencias a la Hidra de Lerna en Hesíodo, a la serpiente Pitón en el Himno homérico a Apolo, Plutarco, Calímaco o Apolodoro.

b) Literatura asiática: China: E. T. C. Werner, Myths and Legends of China, London, 1922, 224 36; Arabia: R. F. Burton, Arabian Nights: the Book of the Thousand Nigths and a 
Nights, London, 1984, I, 172; Japón: M. Anesaki, Japanese Mythology, Boston, 1928, 228; Persia: A. J. Carnoy, Iranian Mythology, Boston, 1917, 266, 270, 273, 322, 325, 329 ss.; India: A. B. Keith, Indian Mythology, Boston, 1917, 3; J. Ph. Vogel, Indiant Serpent Lore or the Nagas in Hindu Legend and Art, London, 1926; E. Benveniste-L. Renou, Urtra et Vrthragna, Paris, 1934; Cf. Himnos del Rigveda, II, 12, 11 (se habla del dios Indra que mató a la serpiente Danu); III, 33, 6 ("Indra...que lleva hacha en mano mató a Vrtra -el dragónguardián de los ríos...”). Cfr. F. R. Adrados, Védico y sánscrito clásico, Madrid, pp. 125-126.

\section{SACRIFICIO HUMANO}

a) Literatura griega: Homero, Iliada, XXIII, 175-176 (prisioneros troyanos que son degollados y echados a la pira de Patroclo); Esquilo, Agamenón, 203-245 (Sacrificio de Ifigenia); Eurípides, Hécuba, 40-41; Heraclidas 502; Suplicantes, 1007-1009; Troyanas, 264; Ifigenia Aulide, 463-464; Oráculos 210 y 362 Parke-Wormell (cfr. H. W. Parke-D. E. W. Wormell, The Delphic Oracle, Oxford, 1956, 2 vols., v. vol. II "The Oracular Responses", pp. 87 y 146); cfr. asimismo M. Benavente, Treinta y seis oráculos de Apolo Delfio, Suplemento de Estudios Clásicos, $2^{\mathrm{a}}$ serie de textos, ñ 1, Madrid, 1966, pp. 14 y 17-18.Cf. P. Grimal, s. v. "Ifigenia", "Agamenón", "Busiris", "Alcioneo 2", "Androgeo", "et passim": cf. "Sacrificio Humano" en el Indice de Temas Legendarios de este libro.

b) Literatura asiática: India: Malalasekera, I, 189, II, 54, 851; Penzer, The Ocean Story, 10 vols., London, desde 1923, IV, 65.

\section{CONCLUSIONES}

1. Existen elementos temáticos de origen popular repetidos parcial o sustancialmente en la tradición literaria de diversos continentes, y tales coincidencias son comunes a culturas y tiempos muy diversos.

2. El estudio de las posibles influencias entre un autor y otro, y entre una obra y otra, nos llevan a concluir que son menos frecuentes las veces en las que se pueda sostener la realidad de una transmisión mítica o una clara interdependencia.

3. En los casos en los que, ante una coincidencia o afinidad temática, no está claro el origen concreto de un tema, o las vías y fechas de transmisión, sólo debe estimarse que hay dependencia literaria en aquellos relatos que repiten sustancialmente los mismos argumentos, y que, por la misma serie de incidentes -y estos dispuestos en el mismo orden lógico de interés-, pueden ser considerados como variantes de una misma narración.

4. El concepto de arquetipo, tal y como se entiende en literatura folclórica, es un ente de razón. Querer remontarse a la génesis de un motivo literario puede calificarse como una tarea inalcanzable, y predispone a incurrir en errores o faltas de método científico, por lo poco seguro y fiable que resulta dicho concepto.

5. La mayoría de los casos de estas afinidades temáticas -que, por otra parte son muy numerosas en la literatura universal-responden a temas muy generales y frecuentes; sin duda proceden de la observación de la naturaleza, y de otras realidades extraliterarias; reflejan la universalidad de la condición humana, la conexión del folclore con la similar forma de reaccionar la mente humana ante situaciones semejantes: no puede negarse la existencia 
de coincidencias temáticas, elementos comunes, semejanzas formales y de fondo, etc, entre los tópicos de índole folclórica de la literatura griega y los de otras muchas literaturas populares del mundo, más o menos distantes de los temas helenos en tiempo y espacio.

6. Por último, hallamos también con cierta lamentable frecuencia, investigadores conspicuos que, a la hora de abordar el estudio de los temas folcloricos, parecen ignorar, gloriosamente, la posibilidad de los desarrollos paralelos o independientes, quizá porque también ignoren que múltiples tópicos literarios, de unas y de otras literaturas, tienen su origen en hechos reales y en entidades extraliterarias. 